In: SILVEIRA, Paula Lemos (Org.). O ensino em contexto pandêmico [livro eletrônico]. São Paulo: Vecher, 2021. Disponível em: <https://doi.org/10.47585/9786599324239>.

\title{
Ensino remoto no contexto pandêmico: reinvenções docentes
}

\author{
Felipe Gustsack1, Vaneza Silva da Rosa e Paula Lemos Silveira ${ }^{3}$ \\ doi.org/10.47585/9786599324239.2
}

Mãos se entrelaçam em conhecimentos produzidos e são, na sua alteridade, afetadas por tempos efêmeros em que novos cenários se apresentam nessa era digital. Neste capítulo, compreendemos as mãos não somente como partes da anatomia do corpo humano, mas também como elementos que se conectam com os fazeres docentes e por isso são manifestações de vidas afetadas por um ensino remoto que as convoca para reinvenções. Tratamos, aqui, de um aspecto de nossa pesquisa cujo objetivo é investigar as reinvenções docentes com a emergência do ensino remoto e como essas afetam os modos de ser docente. As reflexões que apresentamos decorrem de nosso interesse em conhecer e compreender quais são as reinvenções docentes decorrentes do ensino remoto no contexto pandêmico? Trata-se de um estudo qualitativo atravessado pelos desafios do enfrentamento à pandemia.

Palavras-chave: Ensino remoto; Reinvenção docente; Contexto; Pandemia.

\footnotetext{
1 Doutor em Educação (UFRGS). Professor (UNISC). http://lattes.cnpq.br/1488669422124537.E-mail: fegus@unisc.br. 2 Doutoranda em Educação (UNISC). Mestre em Educação (UNISC). http://lattes.cnpq.br/3442036268443429. E-mail: vsrosa@mx2.unisc.br

3 Doutoranda em Educação (UNISC). Mestre em Educação (UNISC). http://lattes.cnpq.br/8483155229482252.

E-mail: paulalsilveira@mx2.unisc.br
} 


\section{Introdução}

Tomando inspirações na gestualidade das mãos, começamos a pensar que essas ao terem contato com as suas ferramentas de trabalho, sentem-se envolvidas por conhecimentos e habilidades que as fazem se tornar ágeis. Porém, essa agilidade não remete somente ao fazer, uma vez que uma ação, especialmente a ação docente, também está envolvida por pensamentos e afetos.

Ao segurar uma caneta, digitar em um teclado, entre tantas outras ações, as mãos expressam os seus modos de sentir e fazer. Essa gestualidade corresponde ao modo de ser de cada docente em sua autoria. Por isso, as mãos têm vida, quase vida própria, uma vez que pensam, agem com o corpo e o contexto ao qual se vinculam. E, nessas vidas as suas histórias, percursos, experiências sentidas em uma presencialidade que hoje se virtualizou. Sim, as mãos se fazem presentes em um ambiente virtual.

As mãos, os dedos, nesse contexto, se sentem virtualizados. Nessa virtualidade somos, então, capturados por uma rede de acesso e desta forma, inventamos um perfil para a nossa presencialidade, que se torna validada pelo registro de uma identificação de usuário e senha. Deste modo, as mãos docentes em cada gesto, bem diferente do que aqueles a que estavam acostumadas na presencialidade de uma sala de aula, emergem por meio de conexões em distintas plataformas digitais virtuais, aplicativos móveis, mídias digitais, percebe e inventando novos espaços de socialização e conhecimentos numa era digital, através de Smartphones, Notebooks, Tablets etc.

Contudo, as gestualidades das mãos docentes, atravessadas e apressadas por um tempo pandêmico, desde 2019, transitaram e ainda transitam por um período delicado de insegurança. Mas, às mãos, nem isso foi permitido. Afinal, como poderiam mostrar-se inseguras essas mãos das quais todos esperam segurança? Talvez pudessem, mas para isso era preciso que se dessem umas às outras. Assim, nesse limite, ocasionado pelo coronavírus, denominado SARSCoV-2, causador da Doença COVID-19, essas mãos foram inventando maneiras de respirar e se manifestar, mesmo banhadas e por vezes irritadas pelo álcool em gel.

Todavia, não só nossas mãos docentes mas o corpo como um todo vem sentindo o peso dos dias ao passar a vivenciar esse período de distanciamento e de isolamento social que não evitou a expansão da COVID-19 por todas as regiões do mundo. O que poderiam as mãos frente a essa pandemia que impactou a sociedade, deixou clara a vulnerabilidade humana, registrando inúmeros casos de infecção e mortes? Ficamos aguardando ansiosamente o passar do tempo, que para as mãos calejadas do docente não possuem trégua. Há um tempo que inexiste para essas mãos docentes diante de tantas demandas, registros, funções das atividades diárias em que a principal atração e solução são as tecnologias digitais. Aí, nas tecnologias digitais há um tempo outro, um tempo do qual fazemos parte muito mais por consequência desse contexto pandêmico do que por uma opção pedagógica consciente, mas também isso já não importa. O que importa é saber que as tecnologias digitais, essas mesmas que possibilitaram que as mãos docentes se reinventassem e pudessem se apresentar ao mundo com toda a sua segurança, certamente farão parte das nossas vidas com muito mais intensidade do que jamais vimos ao longo tempo. 
Todavia, distanciam-se, fogem, escapam das mãos docentes alguns movimentos que se referem às políticas educacionais frente à pandemia ocasionada pelo Coronavírus. Mesmo assim, sua ação passou a ser viabilizada através da portaria 343, que centrou a docência no ensino remoto e valorizou o uso intensivo das tecnologias, oportunizando, então, aprendizagens fecundas aos educadores e educandos. O ensino remoto tornou-se importante não apenas ao viabilizar a continuidade dos percursos educativos mas também ao trazer possibilidades de reflexões sobre a docência, pois as mãos ágeis de nossos docentes não pararam. As aulas passaram a utilizar plataformas digitais fazendo com que a atividade docente se reinventasse para cada docente que se deparou com a necessidade e a urgência de desenvolver novas habilidades e competências. Inventar outros saberes tecnológicos foi um desafio para mediar aulas e ensinar e aprender. Voltando o olhar para o tempo docente, analisando a jornada diária de trabalho, diante do cenário proposto e dadas as condições de desvalorização, no Brasil, das políticas de educação, percebemos que mais do que nunca ensinar e aprender foi e está sendo um desafio.

Com a chegada da pandemia, através das mãos criativas dos docentes, imediatamente o ensino, até então presencial para os discentes, passou a ser de maneira remota, em uma proposta inovadora, disruptiva, que acelerou quebras de paradigmas, exigindo mudanças de posturas, práticas, metodologias e demais ações pedagógicas e reflexivas de reinvenção da própria docência. Com base nos argumentos elencados, destacamos os impactos na educação pois talvez as aulas, agora remotas e a presença intensiva das tecnologias tragam reviravoltas aos paradigmas vigentes, subvertendo mentalidades e valores educacionais.

O que percebemos é que dessa maneira a educação vem sendo afetada por grandes mudanças, pois os recursos virtuais proporcionam outros espaços de reflexões que foram aceleradas nesse momento pandêmico. A ocorrência de uma transformação digital como esta que estamos vivendo aporta modificações nas práticas docentes e na busca por recursos pedagógicos digitais que proporcionem o ensino desejado agora adaptado para a modalidade remota. Há que se buscar, para além do que já se fala, novas maneiras de se subsidiar teórica e empiricamente compreensões do processo epistemológico que estamos vivendo e como este reflete diretamente na docência e através dela.

A educação, em qualquer contexto, requer planejamento e esforços contínuos para o sucesso da aprendizagem e o envolvimento de todos que dela participam. Importa destacar, nessa perspectiva, que a educação é uma ação humana com assento epistemológico num contexto coletivo. Ação que se realiza com uma intencionalidade a ser, necessariamente, explicitada visando atender aos desejos desse mesmo coletivo que estrutura toda a sociedade. Precisamos compreender, assim, que qualquer que seja a ação educativa ela sempre se dá em espaços específicos mas abrange todo um conjunto de atores entre os quais todos estamos e nos educamos como coletividade. Ao mesmo tempo, transformamos e nos transformamos pois somos afetados por tudo aquilo que aprendemos, seja nas instituições educativas ou fora delas. E, porque estamos sempre aprendendo é que se faz necessário um planejar para a realização dessa docência, se faz necessário conhecer a intencionalidade, o contexto, o docente e suas condições de ação, mas também precisamos 
conhecer o discente para escolher a melhor metodologia, os melhores recursos para possibilitar a transformação dele em concomitância com a nossa.

Se não se conhecem esses aspectos, fica difícil oportunizar segurança - ausência de angústia - para os docentes em um contexto pandêmico por mais que possamos confiar em nossas mãos. Mãos que revelam novos sentidos que são compreendidos pelo docente no ensino remoto, que passou a planejar e realizar suas atividades utilizando recursos tecnológicos digitais. Diferentemente da modalidade de Educação a Distância, que tem todo um planejamento e um grupo de trabalho dando suporte, o ensino remoto depende do docente e de suas mãos para se realizar. Ainda que em todas as modalidades educacionais envolvemos as mãos, há que se lembrar que no ensino presencial elas se valiam de todo o corpo, dos valores e cores do contexto, ao passo que no ensino remoto, na maioria das vezes nos deparamos com tela cheia de câmeras e microfones desligados. Daí a importância e a necessidade de valorizarmos esse docente, que muito às pressas aprendeu com suas mãos - consigo mesmo e com seus pares - a manter sempre aquele toque de bom humor, de uma certa magia capaz de encantar atenções, principalmente quando se fala em docência mediada por tecnologias digitais, pois elas só funcionam se e quando pensadas e manipuladas por um humano comprometido e inventivo nesse processo.

Nesse sentido, falamos em reinvenção, porque é dela e com ela que tornamos possível a continuação do percurso educacional em pleno contexto pandêmico. Inventar é uma palavra que tem origem latina (inventare) e remete à imaginação, à engenhosidade de criar algo novo. Aqui, a tomamos como uma maneira de organizar e reorganizar, de transformar a si mesmo e ao mundo, ou seja, reinventar e reinventar-se diante dos desafios que o contexto nos apresenta. A partir dessa palavra e com ela tratamos de uma educação disruptiva, de quebra de paradigmas apresentada pelo uso das tecnologias digitais como uma operação seminal. Isto é, que inaugura uma nova etapa nos processos educacionais que vêm sendo modificados, ampliados, produzindo outros conhecimentos a respeito de algo que já conhecíamos. Tratamos, assim, de uma educação mediada pelas tecnologias digitais como ação que se efetiva em relações de alteridade, articuladas pelas mãos do outro como apoio e compartilhamento de saberes e experiências.

\section{Educação Disruptiva}

O tato das mãos é um dos nossos cinco sentidos com o qual identificamos contextos e objetos concretos, mas também nos identificamos, ao tocarmos em algo que nos toca, a nós mesmos e podemos, com isso, ter uma percepção do outro. Com a sensibilidade do toque mudamos e (re) organizamos nossos sentidos mais íntimos para podermos (re)pensar. Assim, pois, somos tocados enquanto educadores por dimensões e sentidos outros dessa profissão que escolhemos e amamos. Considerando a educação como um processo permanente de formação, seja ela de ensino básico, fundamental ou superior, vamos realizando essa complexa aprendizagem da ação-reflexão-ação acerca da docência em si, a qual tem, como uma das missões, educar melhorando o mundo através de si e das provocações à transformação do outro. Ou seja, inventar e viver o mundo como 
uma experiência de conhecer. Experiência, que segundo Larrosa (2017 p.3), é o que dá sentido à Educação. Afinal, é na e com a experiência viva, em ato, que narramos, nos inscrevemos, e também escrevemos - registramos em dimensões internas e externas a nós mesmos - aquilo que podemos ser a cada dia, a cada momento. Segundo a compreensão de Michel Foucault (apud LARROSA e KOHAN, 2002, p. 1), “A experiência, e não a verdade, é que dá sentido à escritura. Digamos, com Foucault, que escrevemos para transformar o que sabemos e não para transmitir o já sabido". E esse registro de nossa experiência é viabilizado por meio da performance das mãos em movimentos, por certo, como dançarinas de nossos corpos docentes.

Movimentos de mãos integrados aos corpos que também criaram as tecnologias digitais que estão presentes, hoje mais do que nunca, em nossas vidas e no campo da educação. Tecnologias que ainda são vistas e pensadas por muitos como algo estranho à própria humanidade. Ou seja, ainda é necessária uma luta para superar essa espécie de abismo cognitivo, uma busca por compreender as tecnologias digitais como uma maneira de melhorar e de mudar o mundo. A alegria, nesse contexto, é perceber que nós sempre teremos humanos que se sentem engajados nessa luta, não para que tudo seja ou esteja em uma visão única de mundo na qual as tecnologias seriam a única maneira de existir. Mas, para que possamos, cada vez mais, ver e inventar mundos diferentes sem anular ou subjugar os já existentes.

Assim, em um movimento bailado de deslocar e desacomodar de mãos já estávamos passando por grandes desafios com relação às tecnologias antes de chegarmos à era digital. Agora, em pleno vigor de nossas vidas na cultura digital, nos vimos nos percebemos ingressando, enquanto docentes, em novos e complexos desafios que nos levam a buscar e realizar outras formações e nos adaptar a um processo, cujo ritmo não é o desejado, de desenvolvendo de habilidades, também tecnológicas, como maneira de fazer frente à exigência de acolhermos e acompanharmos nossos discentes.

Preocupa, termos tido que aguçar, como num estalar de dedos, as nossas leituras do contexto educacional e político vivendo as reviravoltas tecnológicas que nos demandam inspiração e criatividade para incorporar novas metodologias em sala de aula. Sabemos que essas exigências são o resultado de valorizações sociais emergentes da atualidade, e que se referem e são demandas do coletivo da sociedade a subverterem mentalidades e valores tradicionais. E, gostaríamos de estar vivendo esse movimento com a devida demora, com a calma de uma dança sem sobressaltos, que possibilitasse o tempo necessário para que a experiência ocorresse em nossos corpos.

Todavia, hoje nos vemos e nos sentimos como dedos que tocam em um gatilho cujo disparo já não conseguimos evitar. Sem desejar o coice desse impacto, nossos corpos foram jogados à reinvenção de toda uma linguagem que registra a educação em pleno e intenso fluxo de mudanças em função das tecnologias digitais on-line. Cabe, então, compreender que também esse movimento nos traz reflexões com relação às mudanças que já vinham singrando as águas da pedagogia via demandas da educação a distância (EaD). Compreender que esse mesmo movimento, ainda que abrupto e acelerado pelo contexto pandêmico, apresenta outros espaços e tempos de aprender, viabilizados, também às pressas, pela portaria 343 (BRASIL, 2020) do Ministério da Educação.

As mãos ansiosas então se agitam através do despertar de resultados de estudos de algumas 
questões que já nos desacomodavam quanto às instituições de ensino que se constituem por ser organizações hierárquicas. Instituições que se utilizavam de mecanismos de disciplinarização e vigilância intensiva e que ora precisaram rever seus modos de operar e subsistir. É certo que um grande número de dificuldades para esse movimento estão alicerçadas em alguns termos utilizados na educação, pois somos regidos por parâmetros curriculares exigidos por lei, envolvendo questões disciplinares como a própria grade (estrutura) curricular. Também é certo, então, que essas mudanças levam a rever muitos desses documentos, que se formos analisar, nos condicionavam, pois dividiam e separavam, por disciplinas, períodos, horários, o trabalho pedagógico de forma desarticulada e que hoje repensamos.

(PAREI, AGORA) Uma mão, cinco dedos ímpares, duas mãos, dez dedos que são pares, mas em que um se diferencia do outro assim como os nossos discentes em uma sala de aula que é nosso chão, um espaço físico institucional, dividido em níveis, salas, classes, fileiras, em que cada um ocupa uma posição específica facilitando o que segundo Foucault $(2009$, p.135) nos descreve como a vigilância e o controle em que o docente visualiza seus alunos definindo tais posição, uma classe. A fim de pensarmos as questões apontadas, analisamos uma classe que fecha o aluno em um espaço que é ocupado em fileiras colocadas uma atrás da outra indicando um alinhamento disciplinar. Hoje se transporta para outros espaços virtualizados em que somos identificados por nossos perfis, através de nossos acessos, mantendo uma vigilância e um controle maior, pois deixamos nossas informações.

Sinto seus dedos mas não vejo as suas mãos exatamente como ocorre quando nos virtualizamos, nos sentimos fazendo parte como em uma sala de aula mas visualizamos os discentes através de fotos por câmeras fechadas. Não podemos exigir a abertura de câmeras pois seria desigual, pois muitos têm dificuldade de acesso além de invadirmos as casas e a intimidade. Segundo Silveira (2018, p. 87) estamos constantemente alimentando os sistemas de informação com dados em que nós mesmos informamos, através deles sendo vigiados que com o avanço das tecnologias, esses meios de vigilância se deslocam para outros dispositivos de vigiar na atualidade. Hoje abastecemos sistemas com informações da nossa localidade em que podemos estar em qualquer lugar através da internet e das redes. Trata-se de vigilância constante, um deslocamento do espaço físico, sem ponto fixo em que podemos estar em qualquer lugar, sem paredes, virtualizados, identificados por um perfil, um poder saber que regula a vida do indivíduo e da coletividade, em que migramos de um modelo segundo Foucault (2009) panóptico para um pospanóptico.

Com o clicar de um dedo de uma mão descortinamos várias informações que para Silveira (2018, p. 87) vivemos uma constante exposição social através das redes e de publicações em mídias sociais que é uma das características da sociedade em que vivemos, que se utilizam do registro instantâneo através da imagens expressando gestos e ações cotidianas. Registramos todo tipo de ação, gestos, comportamentos e conversações dos cidadãos por chat, por fóruns, por Whatsapp, por e-mail, troca de mensagens. Como o registro de uma aula através de um vídeo, voz, imagem, a fim de que se conservem as informações narradas. Vivemos em uma espécie de inspeção contínua, exercida pela "sociedade de controle", que é esse poder de monitoramento sobre a ordem social na qual estamos inseridos. 
Dito isso, tais discussões teóricas nos permitem pensar na analogia dos nossos dedos, a representação simbólica dos mesmos, por exemplo em uma questão matemática, embora, quando concretamente não precisamos. Assim, pensamos na palavra disciplina, nossas memórias e representações nos fazem pensar em algo relacionado a ordem. Consideramos, desta forma, que os estudos de Foucault (2009) se aproximam desta discussões, indicando que a palavra disciplina remete ao controle, vigilância e questões normatizadoras.

Afinal nem os dedos das mãos são iguais que dirá os nossos discentes em uma avaliação em que não podemos avaliar da mesma maneira pois nos constituídos de maneira diferente. A avaliação também é sempre muito discutida. Para Foucault (2009, p. 164) trata-se de um mecanismo de poder disciplinar que aqui também podemos citar os trabalhos de conclusão com bancas avaliadoras, que por muitas vezes, intimidam o discente sem mensurar se realmente desenvolveu o conhecimento ou se é uma reprodução de conteúdos.

O movimento incessante de nossas mãos orquestram um momento que é de uma mudança nas ações docentes de uma proposta tradicional para uma proposta inovadora pautada em solução de situações problemas, construção de projetos, trabalho colaborativo, tendo como base Projetos Pedagógicos integrados, interdisciplinares, inovadores, por competências, desenvolvendo habilidades que durante o processo de ensino aprendizagem promova, a autonomia do nosso aluno e aqui falamos de uma autonomia individual voltada na construção coletiva que as tecnologias hoje proporcionam.

As mãos docentes carregam um pesado papel que é o de repensar a Educação, dada como tradicional para uma Educação hoje, disruptiva de quebra de paradigmas, de mudanças de posturas, práticas, ações em que o docente também aprende com o aluno e não como detentor do conhecimento que para Foucault (1984, p 10), podemos nos reinventar, pois para ele existem momentos na vida em que a questão de saber se pode pensar diferentemente do que se pensa, e perceber diferentemente do que se vê, é indispensável para continuar a olhar ou refletir, pensando diferentemente do que se pensa e do que se vê para continuarmos refletindo em busca de novos saberes.

Nossas mãos gesticulam inquietantemente diante do computador, que segundo Masetto (2015), o advento da Internet e as próprias tecnologias contribuíram para essa desacomodação no ensino superior sendo considerado um dos desafios causando mudanças nas ações docentes devido a socialização do conhecimento e acesso imediato de informações que segundo o autor:

O acesso a todas essas informações hoje se encontra à disposição de todas as pessoas de forma imediata. em tempo real, nos colocando, inclusive, em contato direto com os próprios pesquisadores e autores desses conhecimentos. (MASSETO, 2015, p. 2).

O humano interage, se comunica através das mãos, nesse momento, nunca se escreveu tanto através das tecnologias móveis que encurtam as distâncias. Dessa maneira, segundo (MILL, 2015, p. 5). os discentes através das tecnologias móveis, da recente expansão e valorização da Modalidade de Educação a Distância e as novas configurações dos modelos de Modalidade de Educação tais como: (ensino a distância, aprendizagem aberta, educação virtual, educação on- 
line, o b-learning (blended learning ou educação híbrida), o e-learning (aprendizagem virtual), o m-learning (mobile learning ou educação móvel) e o u-learning (ubiquitous learning ou educação ubíqua) são modelos que nos proporcionam tanto para o aluno como o professor o acesso a qualquer tipo de informação de modo instantâneo.

O privilégio tátil de nossas mãos docentes artísticas carrega consigo um importante legado que é o de repensar novas práticas de aprendizagem, que contemplem a construção coletiva do conhecimento, das trocas de experiências e que promovam a autonomia do aluno, reconhecendo-se os diferentes estilos de aprendizagem de múltiplos interesses e não focada no professor como o detentor do conhecimento. Segundo Masetto (2015, p. 2), nenhum professor pode hoje pretender dominar todo o conhecimento de sua área e transmití-lo organizada e resumidamente para seus alunos.

Mãos solitárias docentes passam sobre a superfície com a palma da mão experimentando as sensações do contato, que se manifestam em meu corpo, vamos nos convencendo muitas coisas que percebemos não existem, me sucumbo a uma ilusão, então, deixo à parte, descarto e reinvento e assim é o cotidiano da vida como docente que enfrenta dificuldades de aceitação se agir como mero transmissor de conteúdos ele necessita realizar atividades que desenvolvam autonomia no aluno construindo competências e habilidades que façam com que esse aluno, busque o seu próprio conhecimento significativo, voltado para o mercado de trabalho pois, ele é o protagonista através de suas ações, responsável por sua própria formação e o papel do professor passa a ser partícipe da proposta como mediador, dando suporte e ferramentas para o desenvolvimento da formação humana e profissional sendo esses alguns dos desafios e tendências para a educação no século XXI.

Novamente as mãos docentes entram em prática nessa ação colocando sobrepostas, dando espaço às mãos discentes, em um árduo planejamento enquanto docentes, mudando situações consideradas tradicionais para uma proposta voltada para a atualidade: Educação disruptiva e a substituição da aula Expositiva por Práticas Inovadoras e o desafio da interdisciplinaridade para além da sala de aula.

As mãos docentes inquietas vem trabalhando pois em pleno século XXI, o modelo tradicional de sala de aula com professores expondo conteúdo, alunos fazendo anotações, temas de casa e provas extensas já vinham se modificando.

O processo de aprendizagem por sua vez ocupou a centralidade do processo de ensino: isto quer dizer que se antes o foco se colocava no "ensinar" entendido como transmissão de informações e conteúdos de disciplinas aos alunos, hoje o foco se encontra na valorização de outro processo : o da aprendizagem. (MASETTO. 2015, p. 2).

O usos de uma mão ou de várias mãos? Nesta duplicidade das mãos, está o docente e aprendizagem,por isso é significativo o entendimento da funcionalidade das mãos, das suas maneiras, o que compartilham, pois nesta reconfiguração o foco não está no docente e sim na aprendizagem sendo necessário novas reconfigurações, mudanças de posturas e de novas ações em sala de aula.

Os discente usa suas mãos para protagonizar e ser autor também de ações em sala de aula, considerando os novos modelos de ensino, que propõem um maior protagonismo por parte do aluno 
e o professor passa ser mediador, um auxiliar na aprendizagem e não um reprodutor de ideias com conteúdos prontos, a inovação começa com o professor. Os professores atuam como "orientadores ou mediadores" e acompanham de modo individual e diferenciado. Os alunos estudam o conteúdo nas suas casas, vão para aula praticar o material estudado e tirar dúvidas com os professores.

A colaboração de mãos docentes substituem o trabalho individual em sala de aula pelo trabalho colaborativo de maneira virtual os alunos trocam informações e experiências contribuindo para que deixem de ser apenas receptores de informação e tornem-se agentes de sua própria educação, além disso há um melhor aproveitamento do tempo em sala de aula, com o uso de ferramentas tecnológicas mais dinâmicas em que os alunos compartilham informações trabalhando de forma integrada e que proporcionem melhorias na qualidade da aprendizagem.

Substituir o toque de um dedo pelo toque da mão seria o mesmo trabalhar com conteúdos mais significativos e próximos da realidade do discente para desenvolvimento de projetos e situações problema baseados em casos reais agrupados com diferentes atividades sobre um mesmo tema utilizando as tecnologias de colaboração.

Atualmente, outras são as necessidades que a sociedade apresenta às profissões e novos perfis profissionais são exigidos. Trata-se de competências que ultrapassam aquelas tradicionais da profissão para abranger outros campos como liderança, gestão, pesquisa, criatividade na solução de problemas , abertura para o novo, pró-atividade, trabalho em equipe multi e interdisciplinar, participação coletiva na elaboração e execução de projetos. (MASETTO. 2015, p.5).

Mesmo a mínima reflexão no que se refere a mão docente deixa transparecer sua multiplicidade de sentidos da mesma maneira, que se faz necessário que o docente contribua para formação do aluno tendo em vista as exigências do mercado, novos perfis profissionais, desenvolvendo a participação coletiva e a aprendizagem significativa por projetos.

Ademais, os grupos de mãos docentes são explicitamente requisitadas quando uma das alternativas nesse processo é o da Interdisciplinaridade e Espaços para além da Sala de Aula, fazer com que a aula transcenda seu espaço tradicional de acontecer somente no ambiente para outros espaços que ocorram uma aprendizagem significativa buscando a formação profissional do discente e a formação adequada para o docente lidar com essas questões.

\footnotetext{
A interdisciplinaridade é uma área fundamental que está sustentando e apoiando a integração de duas ou mais áreas de conhecimento no enfrentamento dos problemas emergentes, permitindo o surgimento de novas profissões que envolvem por exemplo a biologia e engenharia, educação e urbanismo, administração, economia e direito. (MASETTO. 2015, p.5).
}

Sendo assim o trabalho de inúmeras mãos artistas tomaria assim todo seu valor como em um lugar de reapropriação da mão, dessa maneira, torna-se importante que docentes proporcionem aos discentes visitas técnicas embora estejamos virtualizados, em escolas, empresas, hospitais, entre outros, propondo vivenciar situações que estão inseridas fora do cotidiano de sala de aula na construção do conhecimento de maneira interdisciplinar, podemos proporcionar passeios virtuais remotamente. 


\section{O ensino remoto emergencial}

Uma obra requer atenção do artista, a atenção desejada na relação entre a mão e sua evidenciação nas artes, assim as mão do artista docente diante do cenário pandêmico que nos proporcionou um clima de incertezas na educação as atividades tiveram continuidade por meio do ensino remoto, as mãos docentes em seus movimentos de sentir, tocar, digitar se reinventaram no uso das ferramentas tecnológicas, operações seminais em que os conhecimentos são ampliados. Constituindo relações de alteridade na interação de mãos em gestualidades, que compartilham experiências e saberes tecnológicos. Neste sentido, os gestos compõem "a relação entre um saber-fazer, um saber-viver e um saber-viver juntos que vai mais além da funcionalidade porque ocorre em formas (em formas-de fazer e em formas de viver) e, portanto, em beleza."(Larrosa, 2018, p. 75). Pois bem, quem sabe, nas reinvenções docentes poderemos sentir as belezas que não se encontram exteriorizadas, visíveis em sua concretude, no entanto, sentidas pelas mãos-docentes no contexto em que estão sendo afetadas.

Com mãos à obra diante do quadro pandêmico, tendo como base a Organização das Nações Unidas para Educação, Ciência e Cultura (UNESCO), em sua estimativa de que 90\% dos estudantes do mundo terão seus estudos impactados ou comprometidos de alguma maneira pela pandemia. Sendo assim, minimizar o quadro que se apresentou a UNESCO (2020) passou a defender que o ensino fosse realizado à distância, ou seja, remoto pois o ensino remoto emergencial adotado pelo governo não pode se confundir com a Educação a Distância e também não são compreendidos como sinônimos, necessitamos compreender conceitos.

O ensino é considerado remoto porque os professores e alunos estão impedidos por decreto de frequentarem instituições educacionais para evitar a disseminação do vírus. É emergencial porque do dia para noite o planejamento pedagógico para o ano letivo de 2020 teve que ser engavetado. (Baher, p.1 2020).

Apresentou-se então um material esponjoso um tanto difícil de moldar para essas mãos docentes, embora reconhecendo as grandes dificuldades em oferecer esse tipo de educação, através do remoto, devido a fatores de formação e apoio aos docentes para utilização de ferramentas tecnológicas, engajamento das famílias pois, todos estamos em casa sendo um grande desafio ensinar os filhos e a maior dificuldade enfrentada foi com relação às desigualdades da conectividade.

A ferramenta de mediação utilizada pelas mãos docentes no Rio Grande do Sul adotaram o google class room e ferramentas do google education. Ensino por outras plataformas, recursos digitais, canal aberto da TV e também por rádio.

Sendo assim, o docente visualizou em suas mãos a responsabilidade de reinventar fezse necessário clicar play com o dedo de sua mão para mudar os movimentos e começar a aprender, para ensinar de outras maneiras. Nos reinventamos pois não estávamos preparados para toda essa transformação. Segundo Baher (2020), o currículo da maior parte das instituições educacionais não foi criado para ser aplicado remotamente. 
Dessa maneira, outro aspecto emerge dessa obra de arte conjunta criada pelas mãos docentes que lidam com diferentes materiais fica aqui o registro do próprio currículo adaptado ao ensino remoto, o ensino até então presencial necessitou ser transportado para meios digitais através dos sistemas de webconferência, e as atividades seguem durante a semana no espaço de um ambiente virtual de aprendizagem (AVA) de forma assíncrona.

Assim como nossa mente controla nosso corpo e nossas mãos, compreendemos a presença física do docente e do discente agora substituídas por logins e senhas de acesso aos sistemas em que controlamos e somos controlados. O discente passou da sala física presencial para uma sala virtual proporcionada pelas tecnologias digitais, então se fazendo presentes. O aluno no espaço da sala de aula presencial é substituído por presença digital numa aula online, para Baher (2020) se chama de 'presença social', que é dada de maneira virtual por meio das tecnologias. E como garanti-la? Através de ferramentas disponíveis nesses espaços para que promovam a participação, as discussões nas aulas online, nos feedbacks e nas contribuições dentro desse ambiente.

A experiência das mãos docentes no ensino remoto requer tempo, um tempo que muitas vezes não temos para planejar, entrando em declínio, fruto da aceleração do capitalismo e da tecnologia, pois a docência, enquanto fazer, requer experiência, requer a experimentação que é o ato ou efeito de experienciar, esse tipo de experiência, de aprender com os erros e os acertos. Não aquele tipo de experiência que corresponde ao acúmulo de situações vividas e que pode ser quantificado numericamente, mas a experiência que volta sobre si mesma para se surpreender com o que acontece, para repensar, num esforço de apontar as insuficiências, as insatisfações, ou mesmo os acertos, descobrindo novos significados, novas possibilidades, novos caminhos.

A extensão de um material pontiagudo, por onde perpassamos a ponta dos nossos dedos docentes tornam-se um contato ameaçador que requer um tempo e que ao mesmo tempo, nos apresenta uma maneira diferente do estar-em-contato, um oculto que toca a visão imaginária subjetivados através pensamento em que assim é o planejar que requer um longo tempo que pode ser permanente na prática docente, o tempo em que vivemos nos limita reflexão sobre o tempo de pensar o planejamento e o imediatismo e a homogeneização do ensino remoto o tempo, assim como o espaço, sendo potência, pode ser sentido como carência e abundância

As nossas mãos foram afetadas por inquietudes, estágios de dor, desânimo, desespero, para depois o desafio e o desenvolvimento, que é umas das maneiras de vencermos o cansaço físico, esgotamento mental, equilíbrio emocional, o momento pandêmico nos impulsiona em práticas enriquecedoras. Sendo assim, as mãos de docentes se reinventam, ressignificam, colocaram sentido em ações que até então não faziam sentido, nos engajamos e fecundamos o novo através do comprometimento de nossas mãos enriquecedoras das práticas pedagógicas.

\section{Considerações finais}

Mediante as nossas mãos docentes que se focam em análises teóricas e metodológicas, compreendemos que as mãos docentes sentiram-se provocadas por mudanças ocasionadas em um fluxo de movimentos efêmeros e desta forma, se tornou necessário procurar refúgio no 
coletivo, o qual se fez relevante na continuidade dos percursos pessoais e profissionais. As mãos docentes marcam a sua presença, reinventando outros gestos e modos de ser. A visibilidade, das mãos, neste contexto, se produz em uma tela de notebook ou celular, mas não deixam de ensinar e aprender, se mostram presentes e desejam ser olhadas.

O contexto educacional é de mudanças, de reinvenção, uso da criatividade, estamos nos transformando, nos desacomodando, por isso, enfrentamos uma disrupção educacional de quebra de paradigmas que envolvem novas posturas do Docente que tem que estar aberto para todas experiências que estamos vivenciando. É fundamental aprender a trabalhar em equipe com os alunos e colegas de profissão, de maneira ativa e interativa, construindo um processo de aprendizagem significativa, de uma educação de qualidade e de sucesso.

Todavia, os ventos fortes modificam nossas obras de arte moldadas por nossas mãos docentes com o passar do tempo, estas obras sugerem novos desafios, que nos geram um tempo de incertezas, os movimentos de nossas mãos e pernas são constantes nos levando para lugares desconhecidos e indefinidos. Esses mesmos ventos, abrem fissuras e nos convocam para entrar. Ao entrar somos capturados por reinvenções, e se retornarmos não seremos mais os mesmos. Podemos pensar que este tempo de incertezas sinaliza o contexto pandêmico, os lugares desconhecidos, quem sabe, o ensino remoto, onde muitos docentes, por certo, sentem-se inquietos e são interpelados por incertezas ao entrar, no entanto, como resposta a este desconhecido, nós docentes, nos reinventamos, mas não deixamos de ser singulares, as nossas reinvenções em lugares, relações, pessoas e conhecimentos se tornam potência, entretanto não apagam a nossa história.

As gestualidades das nossas mãos, entrelaçadas ao movimento dos nossos dedos, tocam, assinalam, significando o espaço em que se encontram. No entanto, não estão separadas do contexto contemporâneo, e assim, sentem-se provocados pela pandemia, e por tudo o que ela faz com a vida. Mudanças, perdas, rupturas, fins de ciclos, início de outros em suas vidas, durante o período de distanciamento. Precisamos de empatia para compreendermos ambos os lados, pois de maneira coletiva estamos passando por momentos atípicos e de grandes adaptações no fazer docente que é dado através da troca de experiências que nos passa de mão em mão, de dedo em dedo e em que cada dedo possui um olho em uma visão que senti.

Podemos sentir as nossas mãos em potência de afetos para aplaudirmos os docentes que se reinventaram diante da pandemia valorizando nossa educação pois o ensino remoto jamais vai substituir os encontros pedagógicos presenciais, são modos diferentes de troca, porém, é uma alternativa para aqueles que possuem engajamento, motivação e condições de acesso que envolvem a agilidade de mão humanas talentosas em seus modos de ser e sentir, portanto em sua singularidade.

As conclusões apontam a necessidade de considerarmos que essa reinvenção somente está se tornando possível porque nos refugiamos, enquanto docentes, na coletividade. Ou seja, que esse intenso processo de reinventar-se a partir de nossas mãos, exige também um movimento de refúgio no coletivo, com o qual se potencializa a continuidade da experiência vivida nos percursos pessoais e profissionais. 


\section{Referências}

BRASIL. Ministério da Educação. Base Nacional Comum Curricular. Brasília, 2018. Disponível em: <http://basenacionalcomum.mec.gov.br/>. Acesso: 10 nov. 2020.

BEHAR, Alejandra Patricia. O Ensino Remoto Emergencial e a Educação a Distância. UFRGS, 6 jul. 2020. Disponível em: <https://www.ufrgs.br/coronavirus/base/artigo-o-ensino-remoto-emergenciale-a-educacao-a-distancia/>. Acesso em: 15 abr. 2021.

FOUCAULT. Michel. Vigiar e Punir: nascimento da prisão. Tradução de Raquel Ramalhete. 37 ed. Petrópolis, RJ: Vozes, 2009.

FOUCAULT, Michel. História da Sexualidade II: O uso dos prazeres. Rio de Janeiro: Edições Graal,1984.

LARROSA, J.; KOHAN, W. Apresentação da Coleção. In.: RANCIĖRE, J. O mestre ignorante. Belo Horizonte: Autêntica, 2002.

LARROSA, Jorge. Esperando não se sabe o quê/sobre o ofício de professor. Belo horizonte: Autêntica, 2018.

MASETTO, M. T. Desafios para a Docência no Ensino Superior na Contemporaneidade. In.: CAVAlCANTE, Maria Marina Dias et al (Org.). Didática e Prática de Ensino: Diálogos sobre a Escola e Formação de Professores e a Sociedade. Fortaleza: EdUECE, 2015.

MIL, Daniel. Gestão estratégica de sistemas de educação a distância no Brasil e em Portugal: A propósito da flexibilidade educacional. Caderno Educ. Soc., Campinas, v. 36, n. 131, p. 407-426, abr.-jun, 2015.

SILVEIRA, Paula Lemos. Os Sentidos da Docência Virtual na Modalidade de Educação a Distância. 2018. Disponível em <https://repositorio.unisc.br/jspui/handle/11624/2100> Acesso em: 10 abr. 2021. 
